\title{
Nutrition Literacy among Adolescents and Its Association with Eating Habits and BMI in Tripoli, Lebanon
}

\author{
Sara Taleb and Leila Itani *
}

Citation: Taleb, S.; Itani, L. Nutrition Literacy among Adolescents and Its Association with Eating Habits and BMI in Tripoli, Lebanon. Diseases 2021, 9, 25. https://doi.org/10.3390/ diseases 9020025

Academic Editor: Maurizio Battino

Received: 6 February 2021

Accepted: 24 March 2021

Published: 29 March 2021

Publisher's Note: MDPI stays neutral with regard to jurisdictional claims in published maps and institutional affiliations.

Copyright: (c) 2021 by the authors. Licensee MDPI, Basel, Switzerland. This article is an open access article distributed under the terms and conditions of the Creative Commons Attribution (CC BY) license (https:// creativecommons.org/licenses/by/ $4.0 /)$.
Department of Nutrition and Dietetics, Faculty of Health Sciences, Beirut Arab University, Riad El Solh, Beirut P.O. Box 11-5020, Lebanon; sarahtaleb494@gmail.com

* Correspondence: l.itani@bau.edu.lb

Abstract: (1) Background: Adolescence is a period of increased autonomy and independent decision making; it determines health behaviors that can persist into the future. Individual factors like food choices and unhealthy lifestyle have an essential role in the development and prevention of obesity among adolescents and are associated with the nutrition literacy of parents and other adults. While the association of parents' nutrition literacy with adolescent BMI has been addressed, there is still a scarcity of studies that examine the effect of adolescents' nutrition literacy on their eating habits and body mass index (BMI) status. (2) Methods: A cross-sectional study was conducted that included 189 adolescents (68 with overweight and obesity and 121 with normal weight) aged between 14-19 years from four private schools in Tripoli, Lebanon. A self-administered questionnaire that included the Nutrition Literacy Assessment Instrument (NLAI) and the Adolescent Food Habits Checklist (AFHC) was used. Anthropometrics were measured using standardized procedures. The association between nutrition literacy, food habits and BMI was assessed using a chi squared test for independence and Poisson regression analysis where suitable. (3) Results: Results indicated no association between all five components of nutrition literacy and body mass index categories. Furthermore, there was no association between the Adolescent Food Habits Checklist and overweight or obese BMI status ( $\mathrm{RR}=0.947,95 \% \mathrm{CI}$ : $0.629-1.426)(p=0.796)$. No association was observed between nutrition literacy and food habits, except for an inverse association with macronutrients literacy. (4) Conclusions: In conclusion, the study indicated that there was no association between the components of nutrition literacy with body mass index or with food habits, except for macronutrient literacy.

Keywords: nutrition literacy; food habits; BMI

\section{Introduction}

Adolescence is a period characterized by increased autonomy and independent decision making and can determine health related behaviors, namely dietary intake [1,2]. During adolescence, nutrition-related behaviors develop as a result of changes in situations and responsibilities as molded by social pressure and social norms; these can influence nutrition knowledge and skills. Both healthy and unhealthy behaviors adopted during adolescence persist into adulthood [3-5]. Adolescents' dietary patterns are characterized by skipping meals, frequent snacking, and consumption of fast food, processed foods and sugar-sweetened beverages [1,6]. These dietary patterns have health implications that persist throughout one's life, like weight gain and increased risk of obesity, cardiovascular diseases, type-two diabetes, some types of cancers, sarcopenic obesity and impaired quality of life [6-11]. Nutrition-related problems and behaviors have been recently reported to be associated with nutrition literacy, especially among adolescents [12-14].

Nutrition literacy, defined as the ability to obtain, process, understand and use correct nutrition information and nutritional knowledge to make healthy food choices, is associated with overall healthy diets [15-17] and diet quality [18]. Moreover, nutrition literacy falls 
under the umbrella of health literacy; low health literacy in adolescents is associated with obesity [19] and lower levels of health-promoting behaviors [20-23]. Low nutrition knowledge and skills increase the susceptibility to excess weight gain and its associated health conditions [24].

In Lebanon, recent studies have suggested that a shift in adolescents' dietary intake, characterized by adherence to a westernized pattern of sedentary lifestyle, is associated with overweight and obesity and its comorbidities [25-30], which can persist throughout one's life and present health challenges [6-11]. With obesity rates far from global targets for 2025 (Global Nutrition report, 2025), adolescence provides an unequalled opportunity to establish healthy eating behaviors through health promoters, which could prevent obesity and related health problems later in life [31,32]. Understanding the determinants of healthy eating in this age group is essential in planning interventions at the public health level or in clinical settings to prevent comorbidities.

Studies in the literature have focused on health literacy and the effect of parent's nutrition literacy on adolescents' body mass index (BMI) rather than adolescents themselves $[19,33]$. However, up to the time of drafting this manuscript, data related to the influence of nutrition literacy on eating patterns and body weight was scarce, particularly in Lebanon. Hence, this study was designed to investigate the association between nutrition literacy among adolescents and their BMI status and food habits.

\section{Materials and Methods}

\subsection{Study Participants}

A sample of 210 adolescents (14-19 years) with a 1:2 ratio of adolescents with overweight (BMI for age $\mathrm{Z}$ score $>+1 \mathrm{SD}$ ) or obesity (BMI for age $\mathrm{Z}$ score $>+2 \mathrm{SD}$ ) or normal weight $(-2 \mathrm{SD} \leq \mathrm{BMI}$ for age $\leq+1 \mathrm{SD}$ ) was used for this cross-sectional study. The sample size was estimated assuming $80 \%$ power and $95 \%$ confidence interval as well as a hypothetical $20 \%$ prevalence of low nutrition literacy among adolescents with normal weight and $40 \%$ among adolescents with overweight and obesity. Based on the sex distribution among adolescents with overweight and obesity in Lebanon [28], it was estimated that the study should include 70 adolescents with overweight or obesity (42 $(60 \%)$ boys and 28 (40\%) girls) and 140 (63 (45\%) boys and 77 (55\%) girls) adolescents with normal weight.

Participants were included based on the following criteria: (1) either overweight or normal weight, (2) aged between 14-19 years and (3) English educated. Students were excluded if (1) aged less than 14 or more than 19 years or (2) underweight, with a BMI < $-2 \mathrm{SD}$ for age $\mathrm{Z}$ score.

\subsection{Data Collection}

Data was collected from four private schools in Tripoli, North Lebanon. Schools were contacted after random selection from the national school guide (MEHE, 2015-2016). Four schools agreed to participate in the study and four classes (grades $9 / 10 / 11 / 12$ ) were included in the study from each school. All participants in the same school and classroom were selected if they fulfilled the inclusion criteria and provided oral consent to participate. Quota sampling was used until the desired sample size was achieved.

Body weight and height were measured using standardized techniques and calibrated equipment. Weight was measured to the nearest $0.1 \mathrm{~kg}$, with participants wearing minimal indoor clothing, using a calibrated electronic scale (Amber Body scale APAFE002; NUMED SARL 2012, Beirut, Lebanon). Height was measured to the nearest $0.1 \mathrm{~cm}$ while the participant stood barefoot with feet together, arms at the sides and head in the Frankfort horizontal plane, using a portable stadiometer (Portable Height scale AHP003; NUMED SARL 2012, Beirut, Lebanon).

A self-administered questionnaire was used, consisting of three components. The first component retrieved information on the sociodemographic characteristics of the participants (age, sex, father employment status, mother employment status, mother education level, father education level, grade, monthly income of the family, place of residence, num- 
ber of rooms in the house and number of individuals living in the house). The other two parts included two instruments: the Nutrition Literacy Assessment Instrument (NLAI) [24] and the Adolescent Food Habits Checklist (AFHC). The NLAI consisted of five subscales: Nutrition and health (NH), Macronutrients (MA), Household food measurement (HFM), Food label and numeracy (FLN), and Food group (FG). The two tools were scored as described elsewhere [24,34]. The total scores for the AFHC and NLAI subscales were categorized into tertiles. Adolescents scoring in the first tertile were given a score of 1 , those scoring in the middle tertile were given a score of 2 and those scoring in the third tertile were given a score of 3 . Adolescents were categorized dichotomously into either low or medium-high tertiles for nutrition literacy and food habits. The frequency of scoring in either the low tertile or medium-high tertile was calculated.

\subsection{Data Analysis}

Smirnov-Kolmogorov and Shapiro-Wilk tests were used to check the normality of the data. Means and standard deviations were calculated for continuous variables. A chi squared test was used to compare proportions. A student's t-test was used to compare means. Means and standard deviations were calculated for continuous variables, or median IQR where appropriate, based on normality tests. The variability and reliability of the NLAI subscales were analyzed using box plots and Cronbach's alpha, respectively (Supplementary Figures S1-S5 and Tables S1-S5). Frequencies and proportion were used for categorical variables. A Student's t-test or Mann-Whitney test were used where appropriate to compare means or medians, respectively. A chi squared test for independence was used for proportions. Simple and multiple Poisson regression analysis was used to calculate the relative risk of being affected by overweight or obesity (BMI for age $\mathrm{Z}$ score $>+1 \mathrm{SD}$ ), with inadequate nutrition literacy or its components as independent variables. Multiple Poisson regression was used while adjusting for potential confounders. All tests were considered statistically significant at $p<0.05$. Statistical Package for the Social Sciences (SPSS) software [35] was used for all the analyses.

\section{Results}

\subsection{Characteristics of the Study Population}

A total of 189 participants completed the survey, aged between 14 and 19 years old and attending private schools, giving a response rate of (90\%). Out of 189 individuals, $121(64 \%)$ were with normal body weight and $68(36 \%)$ demonstrated overweight and obesity.

Anthropometric characteristic differed significantly across BMI categories (Table 1). The median weight among adolescents with normal weight—56.00 kg (IQR: 52.00-62.30)— was lower compared to those with overweight and obesity-76.30 kg (IQR:68.35-90.00). BMI followed the same trend; it was lower for adolescents with normal weight-20.40 (IQR:19.00-21.89)—than for those with overweight and obesity-26.69 (IQR:25.25-29.00). Similarly, BMI for age $Z$ score for adolescents with normal weight $(0.016 \pm 0.7)$ was significantly lower than that for those with overweight and obesity $(1.8 \pm 0.5)$. The participants did not differ significantly with respect to sociodemographic characteristics (Table 1). 
Table 1. Sociodemographic and anthropometric characteristics of the study population $(n=189)^{\ddagger}$.

\begin{tabular}{|c|c|c|c|c|}
\hline Variable & $\begin{array}{c}\text { Overweight/Obese } \\
(n=68)\end{array}$ & $\begin{array}{c}\text { Normal Weight } \\
\quad(n=121)\end{array}$ & $\begin{array}{c}\text { Total } \\
(n=189)\end{array}$ & Significance ${ }^{* *}$ \\
\hline Age (years) & $16(14.25-17.00)$ & $16.00(15.00-16.00)$ & $16.00(15.00-17.00)$ & $p=0.396$ \\
\hline Sex & & & & $\begin{array}{c}\mathrm{X}^{2}=0.024 \\
p=0.878\end{array}$ \\
\hline Male & $39(57.4)$ & $68(56.2)$ & 107 (56.6) & \\
\hline Female & $29(42.6)$ & $53(43.8)$ & $82(43.4)$ & \\
\hline Height $(\mathrm{cm})$ & $168.80 \pm 9.94$ & $166.17 \pm 8.39$ & $167.11 \pm 9.04$ & $p=0.056$ \\
\hline Weight (kg) & $76.30(68.35-90.00)$ & $56.00(52.00-62.30)$ & $61.30(54.60-71.00)$ & $p<0.0001$ \\
\hline $\begin{array}{l}\text { Body Mass Index } \\
\left(\mathrm{kg} / \mathrm{m}^{2}\right)\end{array}$ & $26.69(25.25-29.00)$ & $20.40(19.00-21.89)$ & $22.00(520.0-25.76)$ & $p<0.0001$ \\
\hline BMI Z score & $1.89 \pm 0.57$ & $0.016 \pm 0.69$ & $0.69 \pm 1.11$ & $p<0.0001$ \\
\hline Grade & & & & $\begin{array}{c}X^{2}=0.013 \\
p=0.908\end{array}$ \\
\hline Grade 9-10 & $32(47.1)$ & $58(47.9)$ & $90(47.6)$ & \\
\hline Grade $11-12$ & $36(52.9)$ & $63(52.1)$ & $99(52.4)$ & \\
\hline School & & & & $\begin{array}{c}\mathrm{X}^{2}=0.146 \\
p=0.702\end{array}$ \\
\hline High socioeconomic & $50(73.5)$ & $92(76.0)$ & $142(75.1)$ & \\
\hline Low socioeconomic & $18(26.5)$ & $29(24.0)$ & $47(24.9)$ & \\
\hline Mother education & & & & $\begin{array}{c}X^{2}=0.315 \\
p=0.854\end{array}$ \\
\hline $\begin{array}{l}\text { Elementary and } \\
\text { vocational school }\end{array}$ & $18(26.5)$ & $32(26.4)$ & $50(26.5)$ & \\
\hline Secondary school & $14(20.6)$ & $29(24.0)$ & $43(22.8)$ & \\
\hline University education & $36(52.9)$ & $60(49.6)$ & $96(50.8)$ & \\
\hline Father education & & & & $\begin{array}{c}X^{2}=2.063 \\
p=0.357\end{array}$ \\
\hline $\begin{array}{l}\text { Elementary and } \\
\text { vocational school }\end{array}$ & $24(35.3)$ & $46(38.0)$ & $70(37.0)$ & \\
\hline Secondary school & $19(27.9)$ & $23(19.0)$ & $42(22.2)$ & \\
\hline University education & $25(36.8)$ & $52(43.0)$ & $77(40.7)$ & \\
\hline $\begin{array}{l}\text { Mother employment } \\
\text { status }\end{array}$ & & & & $\begin{array}{c}X^{2}=2.222 \\
p=0.329\end{array}$ \\
\hline Employee & 14 (20.6) & $29(24.0)$ & $43(22.8)$ & \\
\hline Self-employed & $8(11.8)$ & $7(5.8)$ & $15(7.9)$ & \\
\hline Unemployed & $46(67.6)$ & $85(70.2)$ & $131(69.3)$ & \\
\hline $\begin{array}{c}\text { Father employment } \\
\text { status* }\end{array}$ & & & & $\begin{array}{c}X^{2}=2.465 \\
p=0.116\end{array}$ \\
\hline Employee & $29(42.6)$ & $66(54.5)$ & $95(50.3)$ & \\
\hline Self-employed & $39(57.4)$ & $55(45.5)$ & $94(49.7)$ & \\
\hline $\begin{array}{l}\text { Monthly income of } \\
\text { the family }\end{array}$ & & & & $\begin{array}{c}X^{2}=2.441 \\
p=0.118\end{array}$ \\
\hline$<600,000$ L.L. & $19(27.9)$ & $22(18.2)$ & $41(21.7)$ & \\
\hline$>600,000$ L.L. & $49(72.1)$ & $99(81.8)$ & $148(78.3)$ & \\
\hline Place of residence & & & & $\begin{array}{c}X^{2}=2.939 \\
p=0.086\end{array}$ \\
\hline Urban & $55(80.9)$ & $84(69.4)$ & $139(73.5)$ & \\
\hline Rural & $13(19.1)$ & 37 (30.6) & $50(26.5)$ & \\
\hline
\end{tabular}

${ }^{\ddagger}$ For continuous data, values are mean $\pm(\mathrm{SD})$ or Median (IQR), and for categorical data, values are $\mathrm{n}(\%) .{ }^{*}$ None of the fathers were unemployed. ${ }^{*}$ Significance pertains to chi squared or student $t$ test or Mann-Whitney test between two BMI categories: normal weight and overweight/obesity.

\subsection{The Level of Nutrition Literacy and Its Distribution in the Study Sample}

Table 2 presents median (IQR) nutrition literacy scores and the distribution of adequate nutrition literacy in the study sample. Although the median nutrition literacy score for each subscale did not vary across the BMI categories, most of the study sample had adequate nutrition literacy with respect to NH (5.00 (IQR:4.00-6.00)) and MA (5.00 (IQR:4.00-5.00)) compared to a total score of six, as well as in FG (12.00 (IQR:11.00-14.00)) compared to a total score of 15 . This exceeded $80 \%$ of the total possible score, indicating a greater than average level of nutrition literacy related to nutritional health $(\mathrm{NH})$, macronutrients (MA) and food groups (FG). Nonetheless, the study sample exhibited marginal nutrition literacy for household food measure (HFM) (3.00 (IQR:2.00-3.00)) and food label reading (FLN) (3.00 (IQR:2.00-4.00)) compared to a total possible score of six. 
Table 2. Median (IQR) of nutrition literacy scores and the distribution of adequate nutrition literacy by BMI category $(n=189)^{\ddagger}$.

\begin{tabular}{|c|c|c|c|c|}
\hline Variable $*$ * & $\begin{array}{l}\text { Overweight/Obese } \\
\quad(n=68)\end{array}$ & $\begin{array}{l}\text { Normal Weight } \\
\quad(n=121)\end{array}$ & $\begin{array}{c}\text { Total } \\
(n=189)\end{array}$ & Significance ${ }^{* *}$ \\
\hline Total NH score & $5.00(4.00-6.00)$ & $5.00(4.00-6.00)$ & $5.00(4.00-6.00)$ & $\begin{array}{c}p=0.868 \\
X^{2}=0.837 \\
p=0.36\end{array}$ \\
\hline $\begin{array}{l}\text { Inadequate and } \\
\text { marginal nutrition } \\
\text { literacy }\end{array}$ & $13(19.1)$ & $17(14.0)$ & 30 (15.9) & \\
\hline $\begin{array}{c}\text { Adequate nutrition } \\
\text { literacy }\end{array}$ & 55 (80.9) & $104(86.0)$ & $159(84.1)$ & \\
\hline Total MA score & $4.50(3.00-5.00)$ & $5.00(4.00-5.00)$ & $5.00(4.00-5.00)$ & $\begin{array}{c}p=0.569 \\
X^{2}=1.109 \\
p=0.292\end{array}$ \\
\hline $\begin{array}{l}\text { Inadequate and } \\
\text { marginal nutrition } \\
\text { literacy }\end{array}$ & $18(26.5)$ & $24(19.8)$ & $42(22.2)$ & \\
\hline $\begin{array}{l}\text { Adequate nutrition } \\
\text { literacy }\end{array}$ & $50(73.5)$ & $97(80.2)$ & 147 (77.8) & \\
\hline Total HFM score & $2.00(2.00-3.00)$ & $3.00(2.00-3.00)$ & $3.00(2.00-3.00)$ & $\begin{array}{c}p=0.449 \\
X^{2}=0.081 \\
p=0.776\end{array}$ \\
\hline $\begin{array}{c}\text { Inadequate and } \\
\text { marginal nutrition } \\
\text { literacy }\end{array}$ & $58(85.3)$ & $105(86.8)$ & $163(86.2)$ & \\
\hline $\begin{array}{l}\text { Adequate nutrition } \\
\text { literacy }\end{array}$ & $10(14.7)$ & $16(13.2)$ & $26(13.8)$ & \\
\hline Total FLN score & $3.00(2.00-4.00)$ & $3.00(2.00-4.00)$ & $3.00(2.00-.00)$ & $\begin{array}{c}p=0.938 \\
X^{2}=0.014 \\
p=0.907\end{array}$ \\
\hline $\begin{array}{l}\text { Inadequate and } \\
\text { marginal nutrition } \\
\text { literacy }\end{array}$ & $41(60.3)$ & $74(61.2)$ & $115(60.8)$ & \\
\hline $\begin{array}{l}\text { Adequate nutrition } \\
\text { literacy }\end{array}$ & $27(39.7)$ & $47(38.8)$ & $74(39.2)$ & \\
\hline Total FG score & $12.00(11.00-13.00)$ & $12.00(11.00-14.00)$ & $12.00(11.00-14.00)$ & $\begin{array}{c}p=0.970 \\
X^{2}=0.787 \\
p=0.375\end{array}$ \\
\hline $\begin{array}{l}\text { Inadequate and } \\
\text { marginal nutrition } \\
\text { literacy }\end{array}$ & $12(17.6)$ & $28(23.1)$ & $40(21.2)$ & \\
\hline $\begin{array}{c}\text { Adequate nutrition } \\
\text { literacy }\end{array}$ & $56(82.4)$ & $93(76.9)$ & $149(78.8)$ & \\
\hline \multicolumn{5}{|c|}{$\begin{array}{l}\text { NH: Nutrition and health; MA: Macronutrients; HFM: Household food measurement; FLN: Food label an } \\
\text { numeracy; FG: Food group. }{ }^{*} \text { For continuous data, values are median (IQR), and for categorical data, values are } \\
(\%) .{ }^{*} \text { For NH, MA, HFM and FLN: inadequate and marginal nutrition literacy }(0<\text { score }<3) \text {; adequate nutritio } \\
\text { literacy }(4<\text { score }<6) \text {. For FG: inadequate and marginal nutrition literacy }(0<\text { score }<10) \text {; adequate nutritio } \\
\text { literacy }(11<\text { score }<15)^{* *} \text { Significance pertains to chi squared or Mann-Whitney non-parametric test between } \\
\text { BMI categories: normal weight and overweight/obesity. }\end{array}$} \\
\hline
\end{tabular}

\subsection{Association between Nutrition Literacy and BMI Status}

Table 3 presents the relative risk of having overweight or obesity with inadequate nutrition literacy in the different components of the nutrition literacy scale. The results indicated that there was no association between all the components of nutrition literacy (MA, NH, HFM, FLN and FG) and BMI categories (normal vs. overweight/obesity). This result held even after the adjustment for potential confounders (Table 3). 
Table 3. The relative risk of being affected by overweight or obesity with inadequate nutrition literacy in the different components of the nutrition literacy scale $(n=189)$.

\begin{tabular}{|c|c|c|c|}
\hline \multirow{3}{*}{$\begin{array}{c}\text { Nutrition Literacy } \\
\text { Scale }\end{array}$} & \multirow{3}{*}{ Nutrition Literacy Score } & \multicolumn{2}{|c|}{ Model } \\
\hline & & Simple & Multiple* \\
\hline & & \multicolumn{2}{|c|}{ RR $(95 \%$ CI) } \\
\hline \multirow[t]{2}{*}{ MA literacy } & Adequate & 1 & 1 \\
\hline & Inadequate and marginal & $1.066(0.946-1.201)$ & 1.049 (0.929-1.185) \\
\hline \multirow[t]{2}{*}{ NH literacy } & Adequate & 1 & 1 \\
\hline & Inadequate and marginal & $1.065(0.93-1.219)$ & $1.062(0.931-1.21)$ \\
\hline \multirow{2}{*}{ HFM literacy } & Adequate & 1 & 1 \\
\hline & Inadequate and marginal & 0.979 (0.847-1.133) & 0.937 (0.81-1.083) \\
\hline \multirow{2}{*}{ FLN literacy } & Adequate & 1 & 1 \\
\hline & Inadequate and marginal & $0.994(0.897-1.102)$ & $0.974(0.877-1.081)$ \\
\hline \multirow{2}{*}{ FG literacy } & Adequate & 1 & 1 \\
\hline & Inadequate and marginal & $0.945(0.836-1.069)$ & $0.91(0.807-1.026)$ \\
\hline
\end{tabular}

¥ NH: Nutrition and health; MA: Macronutrients; HFM: Household food measurement; FLN: Food label and numeracy; FG: Food group. * Model adjusted for age, sex, mother education, father education, mother employment, father employment, grade, school type and place of residence.

\subsection{Healthy Eating Habit Scores and Distribution by BMI Status}

Table 4 presents the distribution of unhealthy eating habits among participants under study by BMI status. Overall, adolescents scored low on the AFHC (11.50 (IQR:8.00-15.00)) compared to the total score of 23 points. The mean AFHC score did not differ between adolescents with normal weight (11.50 (IQR:7.83-15.00)) or those with overweight and obesity (11.25 (IQR:8.36-14.45)). Overall, the majority of adolescents had a medium/high food habit score $(64.6 \%)$, with the lowest being in adolescents with normal weight $(63.6 \%)$, followed by adolescents with overweight and obesity (66.2\%). However, there was insignificant difference in the distribution of AHFC items across categories of BMI $(p>0.05)$.

Table 4. Distribution of unhealthy eating habits among participants under study by BMI status ( $n=189)$.

\begin{tabular}{ccccc}
\hline Variable & $\begin{array}{c}\text { Overweight/Obese } \\
(\boldsymbol{n}=\mathbf{6 8})\end{array}$ & $\begin{array}{c}\text { Normal Weight } \\
(\boldsymbol{n}=\mathbf{1 2 1})\end{array}$ & $\begin{array}{c}\text { Total } \\
(\boldsymbol{n}=\mathbf{1 8 9})\end{array}$ & Significance \\
\hline Total AFHC score $^{¥}$ & $11.25(8.36-14.45)$ & $11.50(7.83-15.00)$ & $11.50(8.00-15.00)$ & $p=0.842$ \\
\hline AFHC categories & & & & $X^{2}=0.123$, \\
Low & $23(33.8)$ & $44(36.4)$ & $67(35.4)$ & $p .726$ \\
Medium and High & $45(66.2)$ & $77(63.6)$ & $122(64.6)$ & \\
\hline
\end{tabular}

¥ Values are median (IQR). AHFC: Adolescent Food Habits Checklist.

\subsection{Association between Healthy Eating Score (AHFC) and BMI}

When looking at the relative risk for having a low score on the AFHC, the result indicated that there was no association between the AFHC (RR $=0.947,95 \%$ CI: $0.629-1.426$ ) ( $p=0.796$ ) and BMI (normal weight vs. overweight and obesity) (Table 5). The results were adjusted for total score of the different nutrition literacy subscale to account for nutrition literacy.

Table 5. Relative risk and 95\% CI for having a low score on the Adolescent Food Habit Checklist $(n=189)$.

\begin{tabular}{|c|c|c|}
\hline \multirow{3}{*}{ Variables } & \multicolumn{2}{|c|}{ Model } \\
\hline & Simple & Multiple * \\
\hline & \multicolumn{2}{|c|}{ RR (95\%CI) } \\
\hline
\end{tabular}

BMI Z score overweight/obesity

Normal weight

Overweight and obesity
$0.93(0.619-1.398)$
1

$0.947(0.629-1.426)$

* Model adjusted for age, sex, grade, school, socioeconomic level, father employment status, mother employment status, mother education, father education, place of residence, total NH, total MA, total HFM and total FLN. NH: Nutrition and health; MA: Macronutrients; HFM: Household food measurement; FLN: Food label and numeracy; FG: Food group. 


\subsection{Association between Healthy Eating Score and Nutrition Literacy}

Table 6 presents the mean scores for the five components of the nutrition literacy scale by food habit category. Adolescents with a lower AHFC score had a higher MA literacy score (5.00 (IQR:4.00-5.00)) than those with a medium or high AHFC score (4.00 (IQR:3.00-5.00)), with a significant association $\left(X^{2}=10.57 ; p\right.$-value $\left.=0.001\right)$ between higher nutrition literacy and lower food habit score. Although those scoring low on the food habits scale scored significantly higher on household food measures literacy (3.00 (IQR:2.00-3.00) vs. 2.00 (IQR:1.75-3.00)), the association was not significant $\left(X^{2}=0.009 ; p\right.$-value $\left.=0.924\right)$. On the other hand, the rest of the nutrition literacy components (NH, HFM, FLN and FG) did not vary between AHFC groups or have an association with the AFHC score (Table 6).

Table 6. Mean nutrition literacy score by food habits score category $(n=189)^{\ddagger}$.

\begin{tabular}{|c|c|c|c|c|}
\hline Variable * & $\begin{array}{l}\text { Low Food } \\
\text { Habits Score } \\
\quad(n=67)\end{array}$ & $\begin{array}{c}\text { Medium High } \\
\text { Food Habits Score } \\
\quad(n=122)\end{array}$ & $\begin{array}{c}\text { Total } \\
(n=189)\end{array}$ & Significance ** \\
\hline Total NH score & $5.00(4.00-6.00)$ & $5.00(4.00-6.00)$ & $5.00(4.00-6.00)$ & $\begin{array}{c}p=0.328 \\
X^{2}=2.288 \\
p=0.130\end{array}$ \\
\hline $\begin{array}{c}\text { Inadequate and marginal } \\
\text { nutrition literacy }\end{array}$ & $7(10.4)$ & $23(18.9)$ & $30(15.9)$ & \\
\hline Adequate nutrition literacy & $60(89.6)$ & $99(81.1)$ & $159(84.1)$ & \\
\hline Total MA score & $5.00(4.00-5.00)$ & $4.00(3.00-5.00)$ & $5.00(4.00-5.00)$ & $\begin{array}{c}p=0.001 \\
X^{2}=10.57 \\
p=0.001\end{array}$ \\
\hline $\begin{array}{c}\text { Inadequate and marginal } \\
\text { nutrition literacy }\end{array}$ & $6(9.0)$ & $36(29.5)$ & $42(22.2)$ & \\
\hline Adequate nutrition literacy & $61(91.0)$ & $86(70.5)$ & 147 (77.8) & \\
\hline Total HFM score & $3.00(2.00-3.00)$ & $2.00(1.75-3.00)$ & $3.00(2.00-3.00)$ & $\begin{array}{c}p=0.042 \\
X^{2}=0.009 \\
p=0.924\end{array}$ \\
\hline $\begin{array}{c}\text { Inadequate and marginal } \\
\text { nutrition literacy }\end{array}$ & $58(86.6)$ & $105(86.1)$ & $163(86.2)$ & \\
\hline Adequate nutrition literacy & $9(13.4)$ & $17(13.9)$ & $26(13.8)$ & \\
\hline Total FLN score & $3.00(2.00-4.00)$ & $3.00(2.00-4.00)$ & $3.00(2.00-4.00)$ & $\begin{array}{c}p=0.126 \\
X^{2}=1.739 \\
p=0.187\end{array}$ \\
\hline $\begin{array}{c}\text { Inadequate and marginal } \\
\text { nutrition literacy }\end{array}$ & $45(67.2)$ & $70(57.4)$ & $115(67.2)$ & \\
\hline Adequate nutrition literacy & $22(32.8)$ & $52(42.6)$ & $74(39.2)$ & \\
\hline \multirow[t]{2}{*}{ Total FG score } & $\begin{array}{c}12.00 \\
(11.00-14.00)\end{array}$ & $\begin{array}{c}12.00 \\
(11.00-14.00)\end{array}$ & $\begin{array}{c}12.00 \\
(11.0-14.00)\end{array}$ & $p=0.634$ \\
\hline & & & & $\begin{array}{c}X^{2}=0.004 \\
p=0.947\end{array}$ \\
\hline $\begin{array}{c}\text { Inadequate and marginal } \\
\text { nutrition literacy }\end{array}$ & $14(20.9)$ & $26(21.3)$ & $40(21.2)$ & \\
\hline Adequate nutrition literacy & $53(79.1)$ & $96(78.7)$ & $149(78.8)$ & \\
\hline
\end{tabular}

₹ For continuous data, values are median (IQR), and for categorical data, values are n (\%). ${ }^{*}$ For NH, MA, HFM and FLN: inadequate and marginal nutrition literacy $(0<$ score $<3)$; adequate nutrition literacy $(4<$ score $<6)$. For FG: inadequate and marginal nutrition literacy $(0<$ score $<10)$; adequate nutrition literacy $(11<$ score $<15)$ ** Significance pertains to chi squared or student $t$ test between two categories of food habits scores. NH: Nutrition and health; MA: Macronutrients; HFM: Household food measurement; FLN: Food label and numeracy; FG: Food group.

\section{Discussion}

The study evaluated nutrition literacy in a sample of Lebanese adolescents and its association with their food habits and BMI status. Participants had adequate nutrition literacy on all components except HFM and FLN. However, there was no association between all components of nutrition literacy and BMI or food habits of adolescents. The exception to this was macronutrient literacy, which was associated with unhealthy food habits among Lebanese adolescents.

The adequacy of nutrition literacy observed among study participants indicates their basic nutritional knowledge and their capacity to understand information about food items 
and food groups, read food labels and control their portions, and make informed decisions or advocate to others about food choices $[15,36]$. Although adolescents were nutritionally literate, there was no association between nutrition literacy components and eating habits, except for an inverse association with macronutrient literacy. The lack of association can be explained by the fact that literacy alone, in terms of factual food-related knowledge and health-related risks, can make an individual contemplate carrying out heathy eating behaviors [37]. Behavioral capabilities include functional and procedural knowledge, critical thinking, goal setting, and problem solving and self-regulation skills; these are a precondition for acting and gaining self-efficacy [38]. In addition, social determinism, in terms of modeling nutrition behaviors for teenagers to learn, is dependent on social environment, which consists of peers and parents; these influences at a young age can lead to long-term healthy eating behaviors [38-41]. Thus, unless nutrition literacy is coupled with essential behavior capabilities and accompanied by environmental support and collaborative action and partnership at multiple levels of influence, behavior change is unlikely $[38,42,43]$. Consistently, the current findings are in line with previous studies from different regions, including USA, Uganda, Egypt and Europe. These studies reported that adequate nutrition literacy among adolescents was not associated with adequate eating habits. In these studies, although adolescents demonstrated awareness of dietary guidelines or scored high on nutrition knowledge scales, they failed to choose low-fat lunches or desserts, healthy cafeteria items, or follow a Mediterranean diet in their everyday life [33-50].

The unhealthy eating habits observed among adolescents in this study are a common finding in this age group. In Lebanon, recent national studies have reported unhealthy food consumption patterns associated with overweight and obesity [26,27]. Unhealthy dietary patterns among adolescents are associated with adverse health implications, including weight gain and increased risk of obesity, cardiovascular diseases, type-two diabetes, hypertension, chronic kidney disease, some types of cancers [6-9] and sarcopenic obesity, in addition to impaired quality of life [51]. What makes this observation critical is that adolescence is a period of life during which eating behavior and food preferences are established, and these often track into adulthood [52-54], thus influencing adult health [54] and quality of life, both of which have an impact on healthcare resources [9-11]. Despite the lack of association between nutrition literacy, eating habits and weight status, recent literature has clearly attributed the increasing trend in obesity among adolescents in Lebanon to unhealthy food consumption patterns along with lower physical activity levels [26,51,55]. Hence, the current findings should not be underscored, as nutritional knowledge has an essential role in the development and prevention of obesity later in life [1,56]. Moreover, our findings were in agreement with previous studies on adolescents in Saudi Arabia and India [57]. On the other hand, Kalakan et al. (2016) reported significantly higher AFHC scores among adolescents with overweight compared to those with underweight and normal weight in Turkey [58].

The literature examining the effect of nutrition literacy on weight status is still scarce. However, the insignificant association between nutrition literacy and BMI is in line with previous reports from different countries, including USA [33], Egypt [47], countries in Europe [45,46], Turkey [58] and Australia [59].

To our knowledge, this is the first study in Lebanon to associate nutrition literacy with BMI and eating habits in a sample of Lebanese adolescents using validated tools. Nevertheless, the study holds few limitations regarding the representativeness of the sample of the Lebanese population, with a focus on private schools and higher socioeconomic status. In addition, parental nutrition literacy and physical activity were not measured. Higher socioeconomic status was previously reported in Lebanon to be associated with higher nutritional knowledge scores and energy and macronutrient intake compared to lower socioeconomic status among youth, irrespective of healthy eating [60]. Furthermore, the presence of high food insecurity was associated with lower adherence to a Mediterranean diet pattern among Lebanese adolescents [61]. In addition, the role of parental nutrition literacy 
in determining healthy eating was recently reported in the literature $[14,62]$, which could have contributed to the observed nutrition literacy, despite the lower healthy eating score. Finally, although reliability analysis (Supplementary Tables S1-S5) of the NLAI subscales revealed small values for Cronbach's alpha, this is justified by the small number of items $(<10)$ that can have a profound effect on the alpha value $[63,64]$.

\section{Conclusions}

Nutrition literacy in this age group, even if it is considered a necessary behavioral capability, is not sufficient to mold heathy eating behaviors or determine overweight and obesity. This confirms previously explained models for determinants of obesity and behavior change in children's ecological niches $[65,66]$, in addition to genetics, food preferences and increased autonomy, that interact with family, community, culture, and physical, social and political environments as well as food environments [2,43,66-71]. Therefore, appropriate levels of nutrition knowledge and literacy may not be enough to influence adolescents food habits or body weight. Hence, within the framework of a causal theory of obesity, early exposure to nutrition literacy can be studied further as a mediator of the interplay of the multiple influences that can, with time, increase autonomy and enhance eating behavior and diet quality, which line the causal pathway to adult obesity. Therefore, it is essential to unveil this role and enforce healthy eating by interventions delivered through a life course approach, specifically focusing on school-based food and nutrition education.

Supplementary Materials: The following are available online at https: / www.mdpi.com/article / 10.3390/diseases9020025/s1, Figure S1.: Box plot for total Nutrition and Health (NH)score by BAZ score category, Figure S2.: Box plot for total Macronutrient (MA) score by BAZ score category., Figure S3.: Box plot for total Household Food Measurement (HFM) score by BAZ score category., Figure S4: Box plot for total Food Label and Numeracy (FLN) score by BAZ score category., Figure S5: Box plot for total Food Group (FG) score by BAZ score category., Table S1: NH scale., Table S2. MA scale., Table S3.: HFM scale., Table S4.: FLN scale., Table S5.: FG scale. Reference [72] is mentioned in the Supplementary Materials.

Author Contributions: S.T. and L.I. conceptualized the idea. L.I. designed the study and conducted the statistical analysis. S.T. collected the data. S.T. and L.I. wrote the manuscript. L.I. revised and edited the manuscript extensively. All authors have read and agreed to the published version of the manuscript.

Funding: This research received no external funding.

Institutional Review Board Statement: The study did not require ethical approval. Students were contacted after the school approval and after taking their oral consent.

Informed Consent Statement: Oral consent was obtained from participants after explaining the study.

Data Availability Statement: Are available from the corresponding author on reasonable request.

Conflicts of Interest: The authors declare no conflict of interest.

\section{References}

1. McKinley, M.C.; Lowis, C.; Robson, P.J.; Wallace, J.M.W.; Morrissey, M.; Moran, A.; E Livingstone, M.B. It's Good to Talk: Children's Views on Food and Nutrition. Eur. J. Clin. Nutr. 2005, 59, 542-551. [CrossRef]

2. Contento, I.R.; Williams, S.S.; Michela, J.L.; Franklin, A.B. Understanding the Food Choice Process of Adolescents in the Contex of Family and Friends. J. Adolesc. Health 2006, 38, 575-582. [CrossRef]

3. Friedman, H.S.; Martin, L.R.; Tucker, J.S.; Criqui, M.H.; Kern, M.L.; Reynolds, C.A. Stability of Physical Activity across the Lifespan. J. Health Psychol. 2008, 13, 1092-1104. [CrossRef]

4. Paavola, M.; Vartiainen, E.; Haukkala, A. Smoking, Alcohol Use, and Physical Activity: A 13-year Longitudinal Study Ranging from Adolescence into Adulthood. J. Adolesc. Health Off. Publ. Soc. Adolesc. Med. 2004, 35, 238-244. [CrossRef]

5. Kjønniksen, L.; Torsheim, T.; Wold, B. Tracking of Leisure-time Physical Activity during Adolescence and Young Adulthood: A 10-year Longitudinal Study. Int. J. Behav. Nutr. Phys. Act. 2008, 5, 69. [CrossRef]

6. Laska, M.N.; Larson, N.I.; Neumark-Sztainer, D.; Story, M. Does Involvement in Food Preparation Track from Adolescence to Young Adulthood and is it Associated with Better Dietary Quality? Findings from a 10-year Longitudinal Study. Public Health Nutr. 2011, 15, 1150-1158. [CrossRef] 
7. Lichtenstein, A.H.; Ludwig, D. Bring Back Home Economics Education. JAMA J. Am. Med. Assoc. 2010, 303, 1857-1858. [CrossRef] [PubMed]

8. Pendergast, D.; Garvis, S.; Kanasa, H. Insight from the Public on Home Economics and Formal Food Literacy. Fam. Consum. Sci. Res. J. 2011, 39, 415-430. [CrossRef]

9. Haque, M.; McKimm, J.; Sartelli, M.; Samad, N.; Haque, S.Z.; Abu Bakar, M. A Narrative Review of the Effects of Sugar-sweetened Beverages on Human Health: A Key Global Health Issue. J. Popul. Ther. Clin. Pharmacol. 2020, 27, e76-e103. [CrossRef]

10. El Ghoch, M.; Fakhoury, R. Challenges and New Directions in Obesity Management: Lifestyle Modification Programmes, Pharmacotherapy and Bariatric Surgery. J. Popul. Ther. Clin. Pharmacol. 2019, 26, e1-e4. [CrossRef]

11. World Health Organization. Global Accelerated Action for the Health of Adolescents (AA-HA!): Guidance to Support Country Implementation; World Health Organization (WHO): Geneva, Switzerland, 2017.

12. Vaitkeviciute, R.; Ball, L.E.; Harris, N. The Relationship between Food Literacy and Dietary Intake in Adolescents: A Systematic Review. Public Health Nutr. 2015, 18, 649-658. [CrossRef]

13. Kalkan, I. The Impact of Nutrition Literacy on the Food Habits among Young Adults in Turkey. Nutr. Res. Pr. 2019, 13, 352-357. [CrossRef]

14. Koca, B.; Arkan, G. The Relationship between Adolescents' Nutrition Literacy and Food Habits, and Affecting Factors. Public Health Nutr. 2021, 24, 717-728. [CrossRef]

15. Kickbusch, I.; Maag, D. Health Literacy. In International Encyclopedia of Public Health; Heggenhougen, K., Quah, S., Eds.; Academic Press: San Diego, CA, USA, 2008; Volume 3, pp. 204-211.

16. Block, L.G.; Grier, S.A.; Childers, T.L.; Davis, B.; Ebert, J.E.; Kumanyika, S.; Laczniak, R.N.; Machin, J.E.; Motley, C.M.; Peracchio, L.; et al. From Nutrients to Nurturance: A Conceptual Introduction to Food Well-Being. J. Public Policy Mark. 2011, 30, 5-13. [CrossRef]

17. Carbone, E.T.; Gibbs, H.D. Measuring Nutrition Literacy: Problems and Potential Solutions. J. Nutr. Disord. Ther. 2012, 3. [CrossRef]

18. Joulaei, H.; Keshani, P.; Kaveh, M.H. Nutrition Literacy as a Determinant for Diet Quality amongst Young Adolescents: A Cross Sectional Study. Prog. Nutr. 2018, 20, 455-464.

19. Sharif, I.; Blank, A.E. Relationship between Child Health Literacy and Body Mass Index in Overweight Children. Patient Educ. Couns. Couns. 2010, 79, 43-48. [CrossRef]

20. Chang, L.-C. Health Literacy, Self-reported Status and Health Promoting Behaviours for Adolescents in Taiwan. J. Clin. Nurs. 2010, 20, 190-196. [CrossRef]

21. Carbone, E.T.; Zoellner, J.M. Nutrition and Health Literacy: A Systematic Review to Inform Nutrition Research and Practice. J. Acad. Nutr. Diet. 2012, 112, 254-265. [CrossRef]

22. Cha, E.; Kim, K.H.; Lerner, H.M.; Dawkins, C.R.; Bello, M.K.; Umpierrez, G.; Dunbar, S.B. Health Literacy, Self-efficacy, Food Label Use, and Diet in Young Adults. Am. J. Health Behav. 2014, 38, 331-339. [CrossRef]

23. Davis, T.C.; Byrd, R.S.; Arnold, C.L.; Auinger, P.; A Bocchini, J. Low Literacy and Violence among Adolescents in a Summer Sports Program. J. Adolesc. Health 1999, 24, 403-411. [CrossRef]

24. Gibbs, H.D. Nutrition Literacy: Foundations and Development of an Instrument for Assessment. Ph.D. Thesis, University of Illinois, Urbana-Champaign, IL, USA, 2012.

25. Sibai, A.M.; Hwalla, N.; Adra, N.; Rahal, B. Prevalence and Covariates of Obesity in Lebanon: Findings from the First Epidemiological Study. Obes Res. 2003, 11, 1353-1361. [CrossRef]

26. Naja, F.; Hwalla, N.; Itani, L.; Karam, S.; Sibai, A.M.; Nasreddine, L. A Western Dietary Pattern is Associated with Overweight and Obesity in a National Sample of Lebanese Adolescents (13-19 Years): A Cross-sectional Study. Br. J. Nutr. 2015, 114, 1909-1919. [CrossRef]

27. Nasreddine, L.; Naja, F.; Akl, C.; Chamieh, M.C.; Karam, S.; Sibai, A.-M.; Hwalla, N. Dietary, Lifestyle and Socio-Economic Correlates of Overweight, Obesity and Central Adiposity in Lebanese Children and Adolescents. Nutrients 2014, 6, 1038-1062. [CrossRef] [PubMed]

28. Nasreddine, L.; Naja, F.; Chamieh, M.C.; Adra, N.; Sibai, A.-M.; Hwalla, N. Trends in Overweight and Obesity in Lebanon: Evidence from Two National Cross-sectional Surveys (1997 and 2009). BMC Public Health 2012, 12, 798. [CrossRef]

29. Youssef, H.; Zind, M.; Garnier, S.; Fazah, A.; Jacob, C.; Moussa, E.; Delamarche, A.G.; Groussard, C. Overweight and Obesity Related Factors among Lebanese Adolescents: An Explanation for Gender and Socioeconomic Differences. Epidemiol. Open Access 2017, 7, 1-11. [CrossRef]

30. Faraj, S.S. Physical Activity among a Representative Sample of Lebanese Adolescents Aged 12-18 Years: A National Crosssectional Study. Ph.D. Thessis, The American University of Beirut, Beirut, Lebanon, April 2017.

31. World Health Organization. Global Strategy on Diet, Physical Activity and Health. Childhood Overweight and Obesity; World Health Organization (WHO): Geneva, Switzerland. Available online: https://www.who.int/dietphysicalactivity/childhood/en/ (accessed on 18 June 2020).

32. Sacco, J.; Lillico, H.G.; Chen, E.; Hobin, E. The Influence of Menu Labelling on Food Choices among Children and Adolescents: A Systematic Review of the Literature. Perspect. Public Health 2017, 137, 173-181. [CrossRef] [PubMed]

33. D'amato-Kubiet, A.L. Nutrition Literacy and Demographic Variables as Predictors of Adolescent Weight Status in a Florida County. Ph.D. Thessis, University of Central Florida, Orlando, FL, USA, 2013.

34. Johnson, F.; Wardle, J.; Griffith, J. The Adolescent Food Habits Checklist: Reliability and Validity of a Measure of Healthy Eating Behaviour in Adolescents. Eur. J. Clin. Nutr. 2002, 56, 644-649. [CrossRef]

35. IBM Corp. IBM SPSS Statistics for Windows; Version 24.0; IBM Corp: Armonk, NY, USA, 2016. 
36. Zoellner, J.; Connell, C.; Bounds, W.; Crook, L.; Yadrick, K. Nutrition Literacy Status and Preferred Nutrition Communication Channels Among Adults in the Lower Mississippi Delta. Prev. Chronic Dis. 2009, 6, A128.

37. Velardo, S. The Nuances of Health Literacy, Nutrition Literacy, and Food Literacy. J. Nutr. Educ. Behav. 2015, 47, 385-389.e1. [CrossRef]

38. Contento, I.R. Nutrition Education Linking Research, Theory, and Practice, 3rd ed.; Jones \& Bartlett Learning: Burlington, MA, USA, 2016.

39. Bandura, A. Health Promotion by Social Cognitive Means. Health Educ. Behav. 2004, 31, 143-164. [CrossRef] [PubMed]

40. Hills, A.P.; Byrne, N.M.; Lindstrom, R.; Hill, J.O. 'Small Changes' to Diet and Physical Activity Behaviors for Weight Management. Obes. Facts 2013, 6, 228-238. [CrossRef] [PubMed]

41. Kitzman-Ulrich, H.; Wilson, D.K.; George, S.M.S.; Lawman, H.; Segal, M.; Fairchild, A. The Integration of a Family Systems Approach for Understanding Youth Obesity, Physical Activity, and Dietary Programs. Clin. Child Fam. Psychol. Rev. 2010, 13, 231-253. [CrossRef]

42. Hawkes, C.; Smith, T.G.; Jewell, J.; Wardle, J.; A Hammond, R.; Friel, S.; Thow, A.M.; Kain, J. Smart Food Policies for Obesity Prevention. Lancet 2015, 385, 2410-2421. [CrossRef]

43. McLeroy, K.R.; Bibeau, D.; Steckler, A.; Glanz, K. An Ecological Perspective on Health Promotion Programs. Health Educ. Q. 1988, 15, 351-377. [CrossRef] [PubMed]

44. Bari, N.N. Nutrition Status of Adolescent Students in Kampala District, Uganda. Master's Thesis, Oslo and Akershus University College of Applied Sciences, Oslo, Norway, 2012.

45. Hellert, W.S.; Beghin, L.; De Henauw, S.; Grammatikaki, E.; Hallström, L.; Manios, Y.; HELENA Study Group. Nutritional Knowledge in European Adolescents: Results from the HELENA (Healthy Lifestyle in Europe by Nutrition in Adolescence) Study. Public Health Nutr. 2011, 14, 2083-2091. [CrossRef] [PubMed]

46. Kersting, M.; Sichert-Hellert, W.; A Vereecken, C.; Diehl, J.; Béghin, L.; De Henauw, S.; Grammatikaki, E.; Manios, Y.; Mesana, M.I.; Papadaki, A.; et al. Food and Nutrient Intake, Nutritional Knowledge and Diet-related Attitudes in European Adolescents. Int. J. Obes. 2008, 32, S35-S41. [CrossRef]

47. Shaaban, S.Y.; Nassar, M.F.; Abd Elhamid, D.M.; Lasheen, R.A. Nutritional Knowledge and Attitude of Adolescent School Girls Living in Cairo. Res. J. Med. Med. Sci. 2009, 4, 421-427.

48. Ranjana, S.; Mahomoodally, F.M.; Ramasawmy, D. Is Healthy Eating Behaviour Common Among School Adolescents in Mauritius? Curr. Res. Nutr. Food Sci. J. 2013, 1, 11-22. [CrossRef]

49. Pucciarelli, D.; McNeany, T.; Friesen, C. The Relationship between Nutrition Knowledge and School Cafeteria Purchases of Seventh Grade Students in a Rural Indiana School District. J. Child Nutr. Manag. 2013, 37, 20.

50. Bargiota, A.; Delizona, M.; Tsitouras, A.; Koukoulis, G.N. Eating Habits and Factors Affecting Food Choice of Adolescents Living in Rural Areas. Hormones 2013, 12, 246-253. [CrossRef]

51. Fazah, A.; Jacob, C.; Moussa, E.; El-Hage, R.; Youssef, H.; Delamarche, P. Activity, Inactivity and Quality of Life among Lebanese Adolescents. Pediatr. Int. 2009, 52, 573-578. [CrossRef] [PubMed]

52. Kelder, S.H.; Perry, C.L.; I Klepp, K.; Lytle, L.L. Longitudinal Tracking of Adolescent Smoking, Physical Activity, and Food Choice Behaviors. Am. J. Public Health 1994, 84, 1121-1126. [CrossRef] [PubMed]

53. Pollitt, E. Does Breakfast Make a Difference in School? J. Am. Diet. Assoc. 1995, 95, 1134-1139. [CrossRef]

54. World Health Organization. Consideration of the Evidence on Childhood Obesity for the Commission on Ending Childhood Obesity: Report of the Ad Hoc Working Group on Science and Evidence for Ending Childhood Obesity, Geneva, Switzerland. Available online: https:/ / apps.who.int/iris/handle/10665/206549 (accessed on 7 September 2020).

55. Nader, P.A.; Majed, L.; Sayegh, S.; Hadla, R.; Borgi, C.; Hawa, Z.; Mattar, L.; Fares, E.-J.; Chamieh, M.C.; Mourad, C.H.; et al. Results from Lebanon's 2018 Report Card on Physical Activity for Children and Youth. J. Phys. Act. Health 2018, 15, S379-S381. [CrossRef] [PubMed]

56. Hruby, A.; Hu, F.B. The Epidemiology of Obesity: A Big Picture. PharmacoEconomics 2015, 33, 673-689. [CrossRef] [PubMed]

57. Al Muammar, M.N.; El Shafie, M.; Feroze, S. Association between Dietary Habits and Body Mass Index of Adolescent Females in Intermediate Schools. EMHJ East Mediterr. Health J. 2014, 20, 39-45. [CrossRef]

58. Kalkan, I.; Turkmen, A.; Filiz, E. Dietary Habits of Turkish Adolescents in Konya, Turkey. Glob. J. Adv. Pure Appl. Sci. 2016, 7, 190-196. [CrossRef]

59. O'Dea, J.A.; Wilson, R. Socio-cognitive and Nutritional Factors Associated with Body Mass Index in Children and Adolescents: Possibilities for Childhood Obesity Prevention. Health Educ. Res. 2006, 21, 796-805. [CrossRef]

60. Nabhani-Zeidan, M.; Naja, F.; Nasreddine, L. Dietary Intake and Nutrition-Related Knowledge in a Sample of Lebanese Adolescents of Contrasting Socioeconomic Status. Food Nutr. Bull. 2011, 32, 75-83. [CrossRef]

61. Naja, F.; Itani, L.; Kharroubi, S.; El Harake, M.D.; Hwalla, N.; Jomaa, L. Food Insecurity is Associated with Lower Adherence to the Mediterranean Dietary Pattern among Lebanese Adolescents: A Cross-sectional National Study. Eur. J. Nutr. 2020, 59, 3281-3292. [CrossRef] [PubMed]

62. Gibbs, H.D.; Kennett, A.R.; Kerling, E.H.; Yu, Q.; Gajewski, B.; Ptomey, L.T.; Sullivan, D.K. Assessing the Nutrition Literacy of Parents and Its Relationship With Child Diet Quality. J. Nutr. Educ. Behav. 2016, 48, 505-509.e1. [CrossRef] [PubMed]

63. Cortina, J.M. What is Coefficient Alpha? An Examination of Theory and Applications. J. Appl. Psychol. 1993, 78, 98-104. [CrossRef]

64. Loewenthal, K.M.; Lewis, C.A. An Introduction to Psychological Tests and Scales; Routledge India: Oxsfordshire, UK, 2018.

65. Nelson, M.C.; Story, M.; Larson, N.I.; Neumark-Sztainer, D.; Lytle, L.A. Emerging Adulthood and College-aged Youth: An Overlooked Age for Weight-related Behavior Change. Obesity 2008, 16, 2205-2211. [CrossRef] [PubMed] 
66. Davison, K.K.; Birch, L.L. Childhood Overweight: A Contextual Model and Recommendations for Future Research. Obes. Rev. 2001, 2, 159-171. [CrossRef]

67. Egger, G.; Swinburn, B. An "Ecological" Approach to the Obesity Pandemic. BMJ 1997, 315, 477-480. [CrossRef]

68. Ajzen, I. The Theory of Planned Behavior. Organ. Behav. Hum. Decis. Process. 1991, 50, 179-211. [CrossRef]

69. Al-Kloub, M.I.; Froelicher, E.S. Factors Contributing to Adolescent Obesity. Saudi Med. J. 2009, 30, 737-749.

70. Bandura, A. Human agency in Social Cognitive Theory. Am Psychol. 1989, 44, 1175-1184. [CrossRef]

71. Bhadoria, A.S.; Sahoo, K.; Sahoo, B.; Choudhury, A.K.; Sofi, N.Y.; Kumar, C.A. Childhood Obesity: Causes and Consequences. J. Fam. Med. Prim. Care 2015, 4, 187-192. [CrossRef]

72. Loewenthal, K. An Introduction to Psychological Tests and Scales, 2nd ed.; Psychology Press: Philadelphia, PA, USA, 2001. 